\title{
Pharmacological protection of the detoxification activity of animals' liver with the help of phos- pholipid and polysaccharide nature substances complex
}

\author{
Elena Kuzminova ${ }^{1}$, Marina Semenenko ${ }^{1, *}$, Evgeny Dolgov ${ }^{1}$, Serik Kanatbaev ${ }^{2}$, and \\ Andrey Abramov ${ }^{1}$ \\ ${ }^{1}$ Krasnodar Research Center for Animal Husbandry and Veterinary Medicine, 4, Pervomaiskaya str., \\ Krasnodar, 350055, Russia \\ ${ }^{2}$ West Kazakhstan Scientific Research Veterinary Station, branch of Kazakh Scientific Research Vet- \\ erinary Institute, 52/1, Gagarina str., Uralsk, 090005, Kazakhstan
}

\begin{abstract}
Currently, among chemical pollutants a significant danger to the health of animals and humans represent oxygen-containing nitrogen compounds - nitrates and nitrites, which are widely used as mineral fertilizers. The article presents data on the study of chronic nitrate intoxication, reproduced in laboratory animals and its pharmacological correction with a complex of substances of phospholipid and polysaccharide nature. The introduction of sodium nitrate to non-linear rats for 30 days at a dose of $3.8 \mathrm{mg}$ per animal leads to the development of intoxication in rats with dominant signs of liver damage. On this background, the use of the complex of beet fiber and rapeseed lecithin leads to a weakening of nitrate toxicosis, which is demonstrated by an increase in rats' body weight, weakening of the clinical manifestations of intoxication, a decrease in cytolytic syndrome, intrahepatic cholestasis and impaired protein synthesis function of liver.
\end{abstract}

\section{Introduction}

At the present time, among chemical pollutants a significant danger to the health of animals and humans represent oxygen-containing nitrogen compounds - nitrates (NO3) and nitrites (NO2), which are widely used as mineral fertilizers [1].

Numerous studies have found out that the widespread use of mineral fertilizers in agriculture without an adequate level of analysis of their content and timing of application creates a serious problem due to an increase of the nitrates and nitrites concentration in water, soil and plants. Thus, when studying the degree of contamination of fodder plants with nitrates and nitrites in 15 farms located in the northern and central climatic zones of Krasnodar region, most often the excess of the permissible concentration of nitrates and nitrites was registered in the green mass of perennial grasses and corn. The accumulation of their high level is facilitated by adverse weather and climate conditions: too hot or, conversely,

\footnotetext{
*Corresponding author: sever291@mail.ru
} 
too cold weather; sudden changes in temperature; waterlogging of the soil and other factors [2].

Nitrogen containing compounds through water and plants enter the body of animals and humans, where they are converted into biologically inactive nitrates and highly active nitrites, which when interacting with hemoglobin form methemoglobin, unable to carry oxygen, resulting in development of hypoxia. The greatest danger of an increased content of nitrites and nitrates in the body lies in their ability to participate in the nitrosation reaction of amines and amides, resulting in the formation of $\mathrm{N}$-nitroso compounds with carcinogenic and mutagenic properties with high hepatotoxicity and nephrotoxicity. The chronic effects of even low doses of nitrite cause negative effects on animal health, which include inhibition of the mechanisms of natural resistance, violation of reproductive function, respiratory tract disease, damage of the nervous system, decreased productivity and safety [3, 4].

In this regard, the urgent task of veterinary pharmacology is the development of effective detoxification based on the mechanisms of binding and elimination of toxic substances from the body, as well as capable of eliminating the pathogenetic aspects of nitrate and nitrite toxicosis.

A promising way in the detoxification of the body is the use of polysaccharides - the high molecular weight products of polycondensation of monosaccharides, linked to each other by glycosidic bonds and forming linear or branched chains. Polysaccharides can include cellulose, hemicellulose, starch and pectin, which are dietary fibers. Dietary fibers isolated from the various plant raw materials are characterized by a more developed specific surface area and a significant average pore radius in comparison with the raw material, which determines the feasibility of their use as sorbents $[5,6]$.

Dietary beet fibers are produced from the beet pulp - a product of sugar beet processing in sugar factories and beet pulp processed in the canning industry. Beet pulp contains soluble and insoluble dietary fibers, which have sorption properties. Firstly, this is mechanical sorption, carried out by the insoluble part of dietary fiber - cellulose. Secondly, biochemical sorption carried out by intestinal soluble dietary fiber with a small molecular weight - pectin. Dissolving in the intestine to lower molecular weight compounds, these substances enter into biochemical reactions with toxins, which leads not only to sorption, but also to neutralization of the latter. Thirdly, the biological sorption carried out by fruit oligosaccharides has a cleansing effect, which is associated with the normalization of the intestinal microflora that neutralizes the decay products that accumulate in the intestine [7, 8, 9].

Since liver is the main target organ affected by toxicosis, it seems appropriate to include in the antitoxic complex a hepatoprotective component in the form of rapeseed lecithin.

Lecithin obtained from rapeseed contains a spectrum of substances with membraneprotective, antioxidant and immunomodulatory effects. It consists of the predominant group of phosphatidylcholines, which are the most significant and physiologically active phospholipids for the body necessary for the construction and correction of the lipid balance of cell membranes and ensuring their adequate functioning. The content of polyunsaturated fatty acids ( $\omega-6$ and $\omega-3)$ in rapeseed lecithin is in the optimal ratio, which is important for regulating the hormonal balance of the body, adequate metabolism of fat and protein metabolism, etc. [10-14].

The aim of the work was to study the possibility of pharmacological protection of the detoxification activity of laboratory animals' liver with a complex of substances of a phospholipid and polysaccharide nature at nitrate intoxication.

\section{Materials and Methods}

Experimental modeling of nitrate intoxication was performed on 40 non-linear rats with an average body weight of $229.7 \pm 1.62 \mathrm{~g}$, divided into 4 groups of 10 animals each. The studies 
were carried out in vivarium of the Pharmacology Department of the Krasnodar Veterinary Research Institute. Rats were kept in cages on sawdust litter; air temperature was within 20$25^{\circ} \mathrm{C}$, relative humidity was $45-60 \%$. The animals were kept on a diet represented by grain mixtures (wheat, barley, sunflower seeds and corn), root crops, apples, lettuce. To obtain statistically reliable results, groups were formed according to the principle of paired analogues.

Chronic nitrate intoxication was modeled by daily intragastric administration of sodium nitrate to rats for 30 days. The choice of the applied dose of sodium nitrate was based on the fact that $180 \mathrm{mg} / \mathrm{kg}$ of the substance leads to the death of $50 \%$ of the animals; therefore, for the chronic experiment, $1 / 10$ of the half-lethal dose was taken, which averaged in $3.8 \mathrm{mg}$ per rat, the sample was diluted with distilled water up to $0.5 \mathrm{ml}$ per head [15].

For pharmacological correction of toxicosis, was used a complex of substances of a phospholipid and polysaccharide nature made in 2 options (the dose was calculated for a rat with a body weight of 230 grams):

- sample No. $1-1 \mathrm{~g}$ of beet fibers and $0.5 \mathrm{~g}$ of lecithin;

- sample No. $2-0.5 \mathrm{~g}$ of beet fibers and $0.25 \mathrm{~g}$ of lecithin

The feed additive was given as boluses, and distilled water was used as a solvent.

The rats of the 1 st group received sodium nitrate and got no treatment, the rats of the 2nd group at intoxication daily got an additional feed additive (sample No.1), the rats of the 3rd group got a feed additive (sample No.2), the 4th group of rats served as a control and received $\mathrm{NaCl}$ solution in amount equivalent to the sodium content in sodium nitrate.

All animals were under clinical observation, recording the general condition and the dynamics of the body weight. The animals were weighed at the beginning of the experiment, on the 15th and 30th days of the experiment. In addition, in the same period, 3 rats were taken from the groups, in which a biochemical blood test and pathological autopsy were performed.

Statistical processing of the results was carried out using statistical programs; quantitative characteristics were evaluated by comparing the average values of two sample sets with the determination of Student's criterion and significance level (p).

\section{Results}

As a result of the studies, it was found out that over the entire period of the experiment, animal death was not observed in all four groups. The first signs of intoxication appeared in the 1st experimental group on the 13th day of the experiment: animals lost their appetite, were depressed, their fur was ruffled, dry and brittle, the mucous membranes were anemic, shortness of breath appeared. As sodium nitrate was further ingested into the body, signs of animal intoxication intensified.

In the 2nd and 3rd experimental groups (using different samples of antitoxic additives), animals showed a reduced reaction to external stimuli, while the appetite was maintained, mucous membranes were pink, the breath was steady.

By the middle of the experiment, in the 1st group (without treatment), anemia of visible mucous membranes was determined during autopsy, the heart had a dark cherry color, the lungs had a flabby texture, the liver had a dense structure of a dark brown color, and in the stomach there was a catarrh of the mucous membrane and degenerative changes in the kidneys. In rats from the 2 nd and 3 th experimental groups the significant changes in the internal organs were not found, however, in the 3rd group, two rats out of three examined showed anemia in the spleen and liver, as well as hemorrhages on the intestinal mucosa were revealed.

On the 30th day of the experiment, the animals of the 1st experimental group were exhausted, they had no appetite, the fur was tousled and dull, the visible mucous membranes 
were anemic, tremors were observed in some animals, and they could hardly move around the cage. An autopsy revealed anemia of organs with hemorrhages on the mucous membranes of the small intestine, stomach and peritoneum.

By the end of the experiment, the condition of the animals in the 2nd and 3rd groups was satisfying, the appetite was not reduced, but visually the fur was disheveled and dull. At autopsy, significant changes in the internal organs have not been determined. The results of the dynamics of body weight of rats during the experiment are presented in Table 1.

Table 1. The influence of feed additives on the dynamics of body weight of rats at sodium nitrate intoxication $(\mathrm{M} \pm \mathrm{m} ; \mathrm{n}=10)$.

\begin{tabular}{|c|c|c|c|}
\hline \multirow{2}{*}{ Group } & \multicolumn{3}{|c|}{ Body weight, $\mathbf{g}$} \\
\cline { 2 - 4 } & $\begin{array}{c}\text { beginning of the } \\
\text { experiment }\end{array}$ & 15th day & 30th day \\
\hline 1 experimental & $232.6 \pm 1.84$ & $227.1 \pm 1.72$ & $222.4 \pm 2.27$ \\
\hline 2 experimental & $229.6 \pm 1.63$ & $231.3 \pm 1.44$ & $240.2 \pm 0.87$ \\
\hline 3 experimental & $227.9 \pm 1.64$ & $232.5 \pm 1.47$ & $235.6 \pm 1.67$ \\
\hline 4 control & $228.5 \pm 1.38$ & $235.4 \pm 1.56$ & $241.0 \pm 1.95$ \\
\hline
\end{tabular}

It was determined that in the 1st experimental group, a decrease in body weight was observed throughout the entire experiment. So, on the 15th day of the study, the average body weight of rats was $227.1 \pm 1.72 \mathrm{~g}$, and by the end of the experiment, it was $222.4 \pm 2.27 \mathrm{~g}$. In this case, the negative dynamics of body weight was observed, at which the percentage of rats increased by $2.4 \%$ by the middle of the experiment and decreased by $4.6 \%$ by the end of the study relative to the initial indications. In the 2 nd and $3 \mathrm{rd}$ experimental groups, in general, the dynamics of the gain was positive. The greatest increase was recorded in the 2nd experimental group, where the body mass indices on the 15 th day were $231.3 \pm 1.44 \mathrm{~g}$ and on the 30 th day they were $240.2 \pm 0.87 \mathrm{~g}$. In the $3 \mathrm{rd}$ experimental group, the indices of the increase of body weight on the 15th and 30th days of the experiment were at the level of the following values $-232.5 \pm 1.47 \mathrm{~g}$ and $235.6 \pm 1.67 \mathrm{~g}$, respectively. The difference with the background weighing at the end of the experiment was $+4.6 \%$ (2nd group) and $+3.4 \%$ (3rd group).

A biochemical blood test revealed that nitrate intoxication is accompanied by the significant change in the metabolic state of the body and animal liver (Table 2).

Introduction of sodium nitrate to rats led to an increase in the activity of aminotransferases. In the group without treatment, on the 15th day of the experiment, the content of AST increased in 2.5 times, and by the end of the experiment, the difference with intact animals was higher in 2.9 times. The concentration of ALT in comparison with the data obtained in the control group of rats increased in 1.6 times by the middle of the experiment, and in 1.7 times by the end of the experiment.

The pharmacological protection of the detoxification activity of the liver of laboratory animals by the complex of substances of the phospholipid and polysaccharide nature during nitrate intoxication was effective in both experimental groups, but the most pronounced positive changes were recorded in the 2 nd group of rats treated with sample No. 1 (taking this into account a descriptive part of the changes in biochemical parameters is given for this group).

Thus, the concentration of AST by the middle of the experiment was in 1.9 times lower than the same indicator in the 1st group, and in 2.2 times lower by the end of the experiment, but it exceeded the values of control rats of the 4th group. In the content of ALT, a similar dynamics was observed: the difference on the 15th day of observation was $39 \%$, and on the 30 th day of the study it was $51.4 \%$ relative to rats of the 1 st group.

When evaluating bile formation in animals of the 1 st experimental group, hyperbilirubinemia was recorded in all periods of the study. In the blood of rats with the 
treatment it was within normal limits although the concentration of total bilirubin exceeded in healthy animals, The difference in the concentration of total bilirubin by the end of the experiment between the 1 st and 2 nd groups was in 1.9 times.

The level of alkaline phosphatase in the 1st group by the end of the observations exceeded the value of the 4th group in 2.2 times, and in the 2 nd group it was higher only by $32.9 \%$.

Table 2. The influence of feed additives on the biochemical parameters of rats at sodium nitrate intoxication $(\mathrm{M} \pm \mathrm{m} ; \mathrm{n}=3)$.

\begin{tabular}{|c|c|c|c|c|}
\hline \multirow{2}{*}{ Indicators } & Group 1 & Group 2 & Group 3 & Control \\
\hline & \multicolumn{4}{|c|}{15 days } \\
\hline ALP, Units/l & $322.0 \pm 13.1$ & $199.9 \pm 12.9 * *$ & $215.4 \pm 6.4^{*}$ & $149.2 \pm 6.7$ \\
\hline AST, Units/l & $47.4 \pm 3.66$ & $23.90 \pm 2.16^{* * *}$ & $27.4 \pm 2.24 *$ & $18.8 \pm 2.35$ \\
\hline ALT, Units/1 & $105.1 \pm 2.84$ & $75.6 \pm 6.05 * * *$ & $81.8 \pm 5.76 * *$ & $65.4 \pm 2.50$ \\
\hline Total protein, g / l & $59.7 \pm 1.45$ & $71.6 \pm 0.98 * * *$ & $67.6 \pm 1.18 * * *$ & $76.2 \pm 0.84$ \\
\hline Creatinine, $\mu \mathrm{mol} / \mathrm{l}$ & $117.4 \pm 3.51$ & $68.4 \pm 4.72$ & $81.1 \pm 6.13$ & $43.6 \pm 1.70$ \\
\hline Urea, mmol / 1 & $13.9 \pm 0.94$ & $8.2 \pm 0.69 *$ & $8.6 \pm 0.74$ & $7.9 \pm 0.22$ \\
\hline Glucose, $\mathrm{mmol} / \mathrm{l}$ & $4.19 \pm 0.18$ & $8.36 \pm 0.29$ & $7.45 \pm 0.43$ & $8.64 \pm 0.57$ \\
\hline Triglycerides, $\mathrm{mmol} / \mathrm{l}$ & $0.99 \pm 0.07$ & $0.72 \pm 0.09$ & $0.72 \pm 0.10$ & $0.91 \pm 0.11$ \\
\hline Cholesterol, $\mathrm{mmol} / \mathrm{l}$ & $1.72 \pm 0.12$ & $1.20 \pm 0.08 * *$ & $1.55 \pm 0.14$ & $0.89 \pm 0.05$ \\
\hline Total bilirubin, $\mu \mathrm{mol} / \mathrm{l}$ & $10.7 \pm 0.41$ & $6.4 \pm 0.38 * * *$ & $8.4 \pm 0.43^{*}$ & $5.7 \pm 0.18$ \\
\hline \begin{tabular}{|l|} 
Indicators \\
\end{tabular} & \multicolumn{4}{|c|}{30 days } \\
\hline ALP, Units/1 & $325.7 \pm 11.6$ & $194.8 \pm 18.7 * *$ & $214.0 \pm 15.4 * *$ & $146.6 \pm 6.5$ \\
\hline AST, Units/l & $51.8 \pm 3.26$ & $23.3 \pm 2.01 * * *$ & $29.3 \pm 2.33 * *$ & $18.2 \pm 1.72$ \\
\hline ALT, Units/l & $110.2 \pm 2.58$ & $72.8 \pm 5.86^{* * *}$ & $81.3 \pm 5.20 * * *$ & $64.1 \pm 2.69$ \\
\hline Total protein, g / l & $57.1 \pm 1.56$ & $70.8 \pm 1.54 * * *$ & $68.6 \pm 1.18 * * *$ & $75.9 \pm 1.59$ \\
\hline Creatinine, $\mu \mathrm{mol} / \mathrm{l}$ & $87.6 \pm 1.85$ & $66.1 \pm 4.31$ & $78.2 \pm 4.84$ & $43.7 \pm 1.52$ \\
\hline Urea, $\mathrm{mmol} / \mathrm{l}$ & $14.6 \pm 0.89$ & $7.6 \pm 0.60 * *$ & $8.7 \pm 0.74 *$ & $7.7 \pm 0.18$ \\
\hline Glucose, $\mathrm{mmol} / \mathrm{l}$ & $4.05 \pm 0.19$ & $8.09 \pm 0.47 *$ & $7.24 \pm 0.43 *$ & $7.97 \pm 0.35$ \\
\hline Triglycerides, mmol / 1 & $1.11 \pm 0.11$ & $0.61 \pm 0.08^{*}$ & $0.89 \pm 0.10$ & $0.89 \pm 0.08$ \\
\hline Cholesterol, mmol / l & $1.80 \pm 0.08$ & $1.14 \pm 0.06^{*}$ & $1.62 \pm 0.11$ & $1.06 \pm 0.07$ \\
\hline Total bilirubin, $\mu \mathrm{mol} / \mathrm{l}$ & $11.3 \pm 0.50$ & $5.9 \pm 0.37 * *$ & $8.5 \pm 0.44 *$ & $5.6 \pm 0.35$ \\
\hline
\end{tabular}

The significance level: $*-\mathrm{p} \geq 0.001 ; * *-\mathrm{p} \geq 0.01 ; * * *-\mathrm{p} \leq 0.05$ in relation to the first group.

Intoxication of the body led to an increase of cholesterol levels in blood, since in the group without treatment of relatively intact animals on the 15th day of the experiment its content was in 1.9 times higher, and by the end of the experiment the difference was in 1.7 times higher. At the same time, on the 30th day the difference in cholesterol content between the 1 st and 2 nd groups was in 1.9 times. A similar picture indicates the presence of cholestatic syndrome caused by a violation of the biliary function of liver and damage to the bile ducts (intrahepatic cholestasis) under the influence of the toxicant, as well as the effectiveness of the pharmacological correction.

The introduction of sodium nitrate caused a violation of the protein-synthetic function of the liver, which was confirmed by a decrease in the total protein content in animals of the 1st group by $27.6 \%$ (first study period) and by $32.9 \%$ (second study period) in relation to healthy rats. The use of the complex supplement allowed minimizing the development of metabolic disorders - by the end of the experiment the difference between the 1 st and 2 nd groups was $24 \%$. 


\section{Conclusion}

Thus, the obtained data indicate that intoxication with sodium nitrate leads to an increase in the level of aminotransferases in the blood of laboratory rats, indicating damage to hepatocytes and the release of intracellular substances into the blood. This process is accompanied by the intrahepatic cholestasis and the violation of the protein-synthetic function of liver. The use of the complex of substances of the phospholipid and polysaccharide nature increases the detoxification activity of the liver of laboratory animals with nitrate intoxication.

\section{Acknowledgement}

The study was supported by the Russian Foundation for Basic Research as part of a scientific project № 19-316-90029.

\section{References}

1. N.G. Hord, Y. Tang, N.S. Bryan, Am. J. Clin. Nutr. 90, 1-10 (2009).

2. N.N. Zabashta, I.A. Sinelschikova, E.N. Golovko, A.N. Vysokopoyasnaya, Effective Livestock Breeding 1(149), 27-30 (2019)

3. L.Kh. Dzocieva, E.G. Kozayeva, I.G. Dzhioev, News of the International Academy of Ecology and Life Safety 15(2), 80-93 (2010)

4. G. Gui, S. Meng, L. Li, B. Liu, H. Liang, C. Huangfu, Yao Xue Xue Bao 51, 59-67 (2016)

5. L.G. Ipatova, A.A. Kochetkova, A.P. Nechae, Food industry 5, 8-10 (2007)

6. N.N. Kornen, E.P. Viktorova, O.V. Evdokimova, Nutrition issues 84(1), 95-99 (2015)

7. Yu.N. Nikonovich, N.A. Tarasenko, University News 5/6, 6-9 (2014)

8. K.S. Kurguzova, The integrated use of beetroot in specialized foods for the prevention of iron deficiency anemia and assessment of their consumer properties (Krasnodar, 2013)

9. E.V. Kuzminova, M.P. Semenenko, E.P. Viktorova, Veterinary 1, 29-37 (2019)

10. V.V. Malyavina, S.A. Tomilina, A.M. Sampiev, Development, research and marketing of new pharmaceutical products: a collection of scientific papers Pyatigorsk 62, 554559 (2007)

11. A.I, Petenko, A.G. Koshchaev, I.S. Zholobova, N.V. Sazanova, Biotechnology of feed and feed additives (Publishing House Kuban SAU, Krasnodar, 2012)

12. Yu.M. Stepanov, Gastroenterology 4(62), 58-64 (2016)

13. K.-J. Gundermann, A. Kuenker, Pharmacological Reports 63, 643-659 (2011)

14. C. Loguercio, P. Andreone, C. Brisc, Free Radical Biology and Medicine 52(9), 16581665 (2012)

15. D.D. Khayrullin, All-Russian scientific-practical conference "Scientific potential of agricultural production" Izhevsk 3, 116-121 (2008) 